\title{
Promoting brands of perishable items on the promise of generous availability of consumption time
}

Received (in revised form): 17th March, 2006

\section{Mario J. Miranda}

is the programme coordinator in the retail management stream of the Business degree at Victoria University, Melbourne, Australia. His areas of research include studies on buying behaviour at the point of purchase. His interest in this area largely stems from his experience as a corporate executive and consultant with the retail industry.

\section{Laszló Kónya}

is a lecturer in Business Studies at the Department of Economics and Finance, La Trobe University, Melburne, Australia, and has regularly delivered courses to the Australian Bureau of Statistics.

\begin{abstract}
If retailers are apologetic about their merchandise being close to expiry dates and consequently offer it on promotion deals, there is no reason to believe that they cannot be boastful when the items being offered are in pristine condition. This paper prospects the potential of positioning products on the basis of the ample availability of consumption time until use-by date. This research examines the attitudes and behaviour of shoppers to the use-by dates of two product categories, namely, food products that require to be refrigerated to maintain their prescribed shelf life, and food products that can be stored under ambient temperature. It is clear from this study that these consumers' approach to label/packaging information when purchasing short-lived products is different from when purchasing products that do not have to be stored in refrigerated conditions. There is no evidence that shoppers change their purchase behaviour for their preferred items when they have insufficient consumption time, even if prices are discounted. In addition, use-by date prone consumers are not prepared to buy smaller packs of their preferred perishable products with short available shelf life as an interim purchase. Instead, they prefer to switch to an alternative brand with adequate available consumption time. It is suggested that weaker brands of perishable items that can promise ample consumption time would encourage those who are perceptive to use-by dates to try them out.
\end{abstract}

Mario J. Miranda

Victoria University School of Applied Economics, Footscray Park Campus, PO Box 14428, MMC, Victoria 3000 ,

Australia.

Tel: +61 396885004 e-mail:

Mario.Miranda@vu.edu.au

\section{INTRODUCTION}

A survey conducted by a primetime Australian television programme, $A$ Current Affair, ${ }^{1}$ of the quality of groceries stocked in retail stores in principal cities found that, in a few instances, items offered for sale had well passed their use-by date. Some of the delinquent stores were supermarkets belonging to the Australian retail majors, and the expired products included everyday items like milk, meat and vegetable products. There were also instances of processed items like canned food and non-prescriptive medicines that had gone beyond their prescribed shelf life. 


\section{BACKGROUND}

Both manufacturers of food products and retailers realise that a shopper's food choice decision needs to be quick and easy. In their attempt to influence consumer selection, they are at pains to differentiate their wares by making all sorts of taste and dietary claims on the labels, many of which can actually confuse the consumer. Food industry regulators in developed countries have, for some time, been trying to prevail upon manufacturers and retailers to adopt a consistent approach to label information to facilitate consumer decision making. In the UK, for example, the Food Standards Agency ${ }^{2}$ has recommended a way of highlighting on the label the fat, sugar and salt content that the food contains, to make it simpler for people to put healthy eating advice in practice when shopping. Yet, while retailers and producers of food products increasingly advertise nutritional values on their labels/packaging, they do not explicitly canvas the availability of consumption times. Nonetheless, shoppers expect to access products that are of pristine quality. Often, however, they mistakenly buy items that have either passed their expiry dates or have precariously close use-by dates so as not to allow enough time for consumption.

There does not seem to be evidence in the retail literature regarding the extent of products having passed their shelf life being compellingly dumped by consumers. The literature also does not appear to have addressed consumers' attitudes and response to use-by dates of their preferred items. It is not unreasonable to expect that when shoppers perceive their preferred item as not having sufficient consumption time, they will either consider purchasing a variant of their preferred brand, including another package size or another brand; they may even contemplate buying their preferred item from another store. In the case of grocery purchase, there is little likelihood of the shopper deferring the purchase of the item. It is therefore possible that brand attrition takes place because shoppers are compelled to consider alternative brands when their preferred brands do not have the required shelf life. There is also a danger that stores may be losing customers in this regard when shoppers seek their preferred items with acceptable shelf life from alternative stores. Conversely, there lies a conceivable opportunity for competitors to woo customers to their own brands if they can claim that their products offer more generous consumption times until their use-by dates because of better inventory management. Product expiry dates are conventionally indicated on the product labels and/or on the primary packaging.

\section{LITERATURE REVIEW}

According to Wright, ${ }^{3}$ product labels are often required to carry promotional offers and are so designed as to attract the attention of shoppers and help them to identify brands in the aisles. In an earlier study, Davies and Wright ${ }^{4}$ identified that the importance that the consumer ascribes to a product's label is product specific and contingent on how the information on the label fits in with the consumer's prior knowledge and attitudes. Davies and Wright believe that if the consumer has purchased the same brand over many years, their attitudes and beliefs towards issues like value and presentation of the packaging would be overlooked. When considering another brand, however, the consumer's impression of the product is influenced by the analysis of the label. While enunciating a code of practice for label design, Humphries ${ }^{5}$ observed that, of all the information on the label, the product name is the principal means outlining to 
the consumer the exact nature of the product. The label information and expiry dates must also be easy to read and must position the customer to make efficient purchases. In a recent study, Huq et al. ${ }^{6}$ found that perishability is an important piece of information to consumers, as it refers to the physical deterioration of a product, implying either a fixed or random product lifetime, after which the product unit has no value to the consumer. A study by the Australian Government Department of Health and Ageing ${ }^{7}$ confirms that consumers not only check for expiry dates, but also seek more extensive information from labels (eg directions, product description and composition) to make informed and healthy choices. Recent studies by Tsiros and Heilman ${ }^{8}$ show that consumers who shop more frequently check use-by dates more often than less frequent shoppers. These researchers also found a willingness of these customers to stop the ageing process by cooking or freezing the perishable groceries.

\section{RESEARCH PROBLEM}

The intention of this research was to examine the attitudes and responses of shoppers to information on labels and packages during the purchase of their preferred items. The study specifically sought to investigate shoppers' inclination to observe the use-by dates on product labels and their reactions to expiry dates that they perceived to be too short.

To this end, two dependent variables were modelled, namely:

- Observation of the use-by dates on labels of regularly purchased milk, meat and vegetable products; these items are perishable, have a naturally brief product life and usually have to be refrigerated.
- Observation of the use-by dates on labels of regularly purchased packaged foods; these items have preservatives added to their composition and have protracted life spans while being stored in ambient conditions.

\section{RESEARCH METHODOLOGY}

The research methodology included the personal administration of a structured questionnaire among 473 randomly selected grocery shoppers across Melbourne, exiting one of Australia's biggest supermarkets chains, namely, Safeway. The survey was conducted over a two-week period in the second quarter of 2005.

The respondents were specifically asked about the frequency with which they read the use-by dates of milk, meat, vegetable products and packaged foods that they bought regularly. It was explained to the respondents that packaged foods, in this instance, were those that could retain their prescribed shelf life in ambient conditions. They were asked to rank the importance that they ascribed to various aspects of information that appeared on labels, such as name of product/manufacturer, product composition, usage instructions, product description, use-by date and address of manufacturer. The questionnaire also sought information about variables considered important in the literature, such as the customer's frequency of shopping, proneness to price specials, inclination to switch to alternative brands, extent of patronising home brands, and selected demographics, such as occupation and age.

This investigation separately addressed top-of-mind attitudes to labels of perishable milk, meat and vegetable products, and to preserved packaged food products. As the aim of the research was to-find-out how the variables considered 
cogent in the literature on purchase behaviour explain the shoppers' inclination to consider the use-by date on product labels, the research focused on the following binary response measures:

- UBDLIM: Do you examine the use-by dates on the labels of milk, meat and vegetable products that you regularly buy? (yes/no).

- UBDEXT: Do you examine the use-by dates on the labels of packaged food that you regularly buy? (yes/no).

We have modelled these dummy variables with binomial regression (logit) models. $^{9}$

\section{Model}

Binomial regression models, in general, can be looked at from several angles. One possible approach is based on a continuous but unobservable, also called latent, variable $Y^{\star}$, which is supposed to be linearly related to a set of explanatory variables, $X_{1}, X_{2}, \ldots, X_{k}$. Thus:

$$
\begin{aligned}
y_{i}^{\star}= & \beta_{0}+\beta_{1} x_{1, i}+\beta_{2} x_{2, i}+\ldots \\
& +\beta_{K} x_{K, i}+\boldsymbol{\varepsilon}_{i}=\mathbf{X}_{i} \boldsymbol{\beta}+\boldsymbol{\varepsilon}_{i}
\end{aligned}
$$

where $\mathbf{X}_{i}$ is an $n \times K$ matrix of $n$ observations on the $K$ explanatory variables, $\boldsymbol{\beta}$ is a $(K+1) \times 1$ vector of the coefficients, and $\varepsilon_{i}$ is a stochastic error term.

In the present context, the latent variable can be an unobserved measure of the importance of use-by date ascribed by the respondent. It is mapped onto an observable binomial variable $Y$, like any of the two dependent variables, by the following rule:

$$
y_{i}=\left\{\begin{array}{l}
1 \text { if } y_{i}^{\star}>0 \\
0 \text { if } y_{i}^{\star} \leq 0
\end{array}\right.
$$

The combination of expressions (1) and (2) yields the following binomial regression model:

$$
\begin{aligned}
P\left(y_{i}\right. & \left.=1 \mid \mathbf{X}_{i}\right)=P\left(y_{i}^{\star}>0 \mid \mathbf{X}_{i}\right) \\
& =P\left(\mathbf{X}_{i} \boldsymbol{\beta}+\varepsilon_{i}>0 \mid \mathbf{X}_{i}\right)=F\left(\mathbf{X}_{i} \boldsymbol{\beta}\right) \\
P\left(y_{i}\right. & \left.=0 \mid \mathbf{X}_{i}\right)=P\left(y_{i}^{\star} \leq 0 \mid \mathbf{X}_{i}\right) \\
& =1-F\left(\mathbf{X}_{i} \boldsymbol{\beta}\right)
\end{aligned}
$$

where $F$ denotes the cumulative probability distribution function of $\varepsilon_{i}$. As regards this error term, there are many possible choices, but the two most popular options are the standard normal and logistic random variables. In the latter case, $F$ is the cumulative standard logistic distribution function:

$$
F\left(\mathbf{X}_{i} \boldsymbol{\beta}\right)=\frac{e^{\mathbf{X}_{i} \boldsymbol{\beta}}}{1+e^{\mathbf{X}_{i} \boldsymbol{\beta}}}
$$

The resultant model is called a binomial logit model. It is a non-linear regression model whose unknown parameters can be estimated using the maximum likelihood method. ${ }^{10}$ Due to non-linearity, the coefficients cannot be interpreted in the usual way, namely, as the marginal effects of the explanatory variables on the dependent variable. However, the signs of the regression coefficients determine the directions of these effects: a positive slope estimate means that the probability of 'success' $(Y=1)$, is an increasing function of the corresponding explanatory variable, while a negative slope estimate implies just the opposite.

\section{Independent variables}

Six groups of independent variables were considered in the analysis. The first includes various aspects of shopping behaviour and satisfaction, such as: - LABREG: Do you read the labels of 
products that you regularly buy? (yes/no).

- CARE: Do you generally take care to store the items that you have purchased in conditions described by the label? (yes/no).

- LONG: How long have you been shopping at this store? (less than 6 months/between 6-12 months/more than a year).

- OFTEN: How often do you shop at this store?

(monthly/fortnightly/weekly/more often).

- TIME: How much time do you spend on average during each visit to this store? (less than $15 \mathrm{~min} / 15-30$ $\mathrm{min} / 31-45 \mathrm{~min} /$ more than $45 \mathrm{~min}$ ).

- BILL: How much is the average size of your grocery bill? (less than $\mathrm{A} \$ 50 / \mathrm{A} \$ 51-\mathrm{A} \$ 100 / \mathrm{A} \$ 101-$ $A \$ 150 /$ more than $A \$ 150)$.

- REPRSP: Do you respond to price specials for items that are not your preferred brand? $(1=$ never; $2=$ sometimes; $3=$ often; $4=$ very often).

- SATISF: Overall satisfaction of your shopping experience in this store on a scale of 1 to 5 ( $1=$ least satisfied; $5=$ most satisfied).

The second group of independent variables consists of a single variable that measures the proportion of purchases of the store brands. It is defined as.

- HOMEB: On average, what percentage of your shopping bill do you spend on home brand products? (0-20/21-40/41-60/over 60).

The third group is concerned with sighting of various features on the labels of regularly purchased products, namely:

- REGNAM: Do you take note of the name of the manufacturer? (yes/no).
- REGADR: Do you take note of the address of the manufacturer or distributor? (yes/no).

- REGCOU: Do you take note of the country of the manufacturer? (yes/no).

- REGCOM: Do you take note of product composition? (yes/no).

- REGDES: Do you take note of product description? (yes/no).

- REGDIR: Do you take note of directions of product usage? (yes/no).

- REGPRO: Do you take note of promotion deals? (yes/no).

The fourth group comprises the ranked importance $(1=$ not important; $4=$ very important) ascribed to each of the above-mentioned features (IMPNAM, IMPADR, IMPCOU, IMPCOM, IMPDES, IMPDIR, IMPPRO), and also to some other label features, namely:

- IMPCOL: How important to you is the label's background colour?

- IMPFON: How important to you is the label's text font size?

- IMPLAN: How important to you is the label's language?

The fifth group of independent variables is based on the decision that shoppers are likely to make in response to finding the use-by date of their regularly purchased item being too short and their response to their regularly purchased item being offered at a discounted price:

- PREFUBD: What do you usually do when the use-by date of your preferred item is too short? $(1=$ buy the item in the usual quantity; $2=$ buy the item in smaller than usual quantity; $3=$ buy smaller size(s) of the item; $4=$ do not buy the item from this store; $5=$ buy an alternative brand from this store with use-by date appropriate to your product 
Table 1: Binomial logit estimation results for UBDLIM

\begin{tabular}{lcccc}
\hline Variable & Coefficient & Standard error & z-Statistic & Probability \\
\hline C & 30.748 & 10.583 & 2.905 & 0.004 \\
BILL & -3.176 & 1.119 & -2.837 & 0.005 \\
AGE & 1.262 & 0.514 & 2.455 & 0.014 \\
HOMEB & -1.292 & 0.591 & -2.188 & 0.029 \\
OFTEN & 1.307 & 0.687 & 1.903 & 0.057 \\
CARE & 2.564 & 1.505 & 1.704 & 0.088 \\
LABREG & -5.740 & 1.865 & -3.077 & 0.002 \\
REGDES & 3.838 & 1.650 & 2.326 & 0.020 \\
REGDIR & 3.749 & 1.658 & 2.262 & 0.024 \\
REPRSP & 1.325 & 0.711 & 1.864 & 0.062 \\
IMPNAM & -2.751 & 1.236 & -2.225 & 0.026 \\
IMPCOU & 1.267 & 0.731 & 1.733 & 0.083 \\
IMPCOM & -1.045 & 0.583 & -1.794 & 0.073 \\
IMPUBD & 0.814 & 0.490 & 1.660 & 0.097 \\
IMPCOL & -1.894 & 0.908 & -2.086 & 0.037 \\
IMPFON & -1.692 & 0.808 & -2.095 & 0.036 \\
IMPLAN & 1.208 & 0.620 & 1.948 & 0.051 \\
PREFUBD $=3$ & -4.563 & 2.527 & -1.806 & 0.071 \\
PREFUBD $=5$ & 0.590 & 1.368 & 0.431 & 0.066 \\
\hline
\end{tabular}

Dependent variable: UBDLIM - Do you examine the use-by dates on the labels of milk, meat and vegetable products that you regularly buy?

Method: ML - binary logit (quadratic hill climbing)

Included observations: 363

Log likelihood =-24.214; Likelihood Ratio test statistic (18 df) =63.594; Restricted log. likelihood = -56.011; probability (Likelihood Ratio test statistic) $=0.000$; McFadden R2 $=0.568$

consumption rate; $6=$ buy the item from another store).

- PREFDIS: What do you usually do when your preferred item is being offered at a discounted price, but has too short a use-by date? $(1=$ buy the item in the usual quantity; 2 = buy the item in smaller than usual quantity; $3=$ buy the item in greater than usual quantity; $4=$ do not buy the item).

In the regression analyses, these categorical variables were represented by dummy variables denoted as PREFUBD $=2, \ldots ;$ PREFUBD $=6$; PREFDIS $=2, \ldots ;$ and PREFDIS $=4 .^{11}$

Finally, the sixth group of independent variables includes demographic factors like:

- GENDER: Gender (male/female).

- AGE: Age group (less than 20/20-29/30-39/40-49/50-59/60 or over).

— EMPL: Are you employed? (yes/no).

\section{Binomial logit analysis}

Binary logit models were estimated for two dummy dependent variables, UBDLIM and UBDEXT. The analyses were conditional, in the sense that only those respondents who at least 'sometimes' read the product labels were considered. In each case, while the analyses started with an 'unrestricted' specification, those independent variables which seemed to be less important and proved insignificant, both individually and jointly, were dropped in the subsequent iterations. For the sake of brevity, only the final, 'restricted' specifications are reported in this paper. ${ }^{12}$

The first dependent variable is whether the shopper usually examines the use-by dates on the labels of regularly purchased refrigerated milk, meat and vegetables products. The results are shown in Table 1.

McFadden $R^{2}(0.568)$ indicates that this model performs quite well; the $L R$ and $z$-statistics suggest that the remaining 
Table 2: Binomial logit estimation results for UBDEXT

\begin{tabular}{lllll}
\hline Variable & Coefficient & Standard error & z-Statistic & Probability \\
\hline C & 1.071 & 1.717 & 0.624 & 0.533 \\
AGE & -0.703 & 0.224 & -3.139 & 0.002 \\
EMPL & -1.292 & 0.546 & -2.364 & 0.018 \\
SATISF & 0.602 & 0.305 & 1.977 & 0.048 \\
OFTEN & 0.651 & 0.296 & 2.195 & 0.028 \\
CARE & 1.574 & 0.545 & 2.888 & 0.004 \\
REGNAM & 1.095 & 0.566 & 1.936 & 0.053 \\
REGCOU & 1.324 & 0.563 & 2.350 & 0.019 \\
REGPRO & 1.658 & 0.610 & 2.719 & 0.007 \\
IMPNAM & -0.643 & 0.268 & -2.398 & 0.017 \\
IMPADR & 0.551 & 0.306 & 1.804 & 0.071 \\
IMPUBD & -0.557 & 0.306 & -1.824 & 0.068 \\
IMPFON & 0.562 & 0.295 & 1.905 & 0.057 \\
\hline
\end{tabular}

Dependent variable: UBDEXT - Do you examine the use-by dates on the labels of packaged food that you regularly buy?

Method: ML - binary logit (quadratic hill climbing)

Included observations: 363

Log likelihood = -58.343; Likelihood Ratio test statistic (12 df) $=49.177$; Restricted log. likelihood = 82.931 ; probability (Likelihood Ratio statistic) $=0.000$; McFadden $R^{2}=0.296$

explanatory variables are significant, both jointly (practically at any level) and individually (at the 10 per cent level).

As regards the signs of the coefficients, they imply that the estimated probability of examining the use-by dates on the labels of regularly purchased perishable products, such as refrigerated milk, meat and vegetables, increases by: the age of the shopper (AGE); the shopping frequency at the given store (OFTEN); the frequency of responding to price specials for items that are not of the preferred brand (REPRSP); the importance generally assigned to information on product labels (such as the country of manufacture and use-by date [IMPCOU, IMPUBD]), to the label's language (IMPLAN); and for shoppers who take care to store the items as prescribed by the labels

(CARE), who take note of product description and the directions of product usage on the labels of products that they regularly purchase (REGDES,

REGDIR), and who would respond to a limited use-by date by purchasing an alternative brand with ample use-by date from this store (PREFUBD = 5). By contrast, the estimated probability of examining the use-by dates on the labels of regularly purchased perishable products decreases by: the average grocery bill (BILL); the proportion of home brands in the shopping basket (HOMEB); the inclination to read the labels of regularly purchased products (LABREG); the importance generally assigned to information on product labels, such as the name of the manufacturer, product composition (IMPNAM, IMPCOM) and the label's background colour and font size (IMPCOL, IMPFON); and for shoppers who would respond to a limited use-by date by purchasing smaller size(s) of their preferred item $(\mathrm{PREFUBD}=3)$.

The second dependent variable is whether the shopper usually examines the use-by dates on the labels of regularly purchased packaged foods, health products and medicines. The results can be found in Table 2 .

The overall quality of this model is not as good as that of the previous one (McFadden $R^{2}=0.296$ ), but can still be considered reasonable. The coefficients suggest that the estimated probability of 
Table 3: Log odds ratios of UBDLIM

\begin{tabular}{lllll}
\hline REPRSP & $\begin{array}{l}\text { OFTEN } \\
\text { monthly }\end{array}$ & fortnightly & weekly & more often \\
\hline Never & 14.573 & 15.880 & 17.187 & 18.494 \\
Sometimes & 15.898 & 17.204 & 18.511 & 19.818 \\
Often & 17.222 & 18.529 & 19.836 & 21.143 \\
Very often & 18.547 & 19.854 & 21.161 & 22.468 \\
\hline
\end{tabular}

examining the use-by dates on the labels of regularly purchased non-perishable products, such as canned and packaged foods, increases by: the overall satisfaction of shopping experience in the given store (SATISF); the shopping frequency at the given store (OFTEN); the importance generally assigned to the address of the manufacturer or distributor on product labels (IMPADR) and to the label's text font size (IMPFON); and for shoppers who take care to store the items as prescribed by the labels

(CARE), who take note of the name of manufacturer, country of manufacture and promotion deals on the labels of products that they regularly purchase (REGNAM, REGCOU, REGPRO). By contrast, it decreases by: the age of the shopper (AGE); employment status (EMPL); and the importance generally assigned to information on product labels, such as the name of the manufacturer and use-by date (IMPNAM, IMPUBD).

\section{Odds ratios}

Apart from the signs of the regression coefficients, it is also customary to interpret ordered regression models by considering the logarithm of the so-called odds ratio. For the binary logit model, it is given by:

$$
\ln \frac{P\left(y_{i}=1 \mid \mathbf{X}_{i}\right)}{P\left(y_{i}=0 \mid \mathbf{X}_{i}\right)}=\boldsymbol{\beta}_{0}+\mathbf{X}_{i} \boldsymbol{\beta}
$$

It can be calculated for any combination of independent variable values. Table 3 shows the $\log$ odds ratio of examining the use-by dates on the labels of regularly purchased refrigerated milk, meat and vegetable products (UBDLIM), comparing the frequency of shopping (OFTEN) and the frequency of responding to alternative items offered on price specials (REPRSP). All other variables in the model have been fixed at their sample medians. ${ }^{13}$

It is evident from Table 3 that the logarithm of the odds ratio of examining the use-by dates on the labels of perishable products that are regularly purchased (UBDLIM) is the largest for most frequent shoppers (OFTEN) and the highest frequency of response to price specials for alternative items that are not the shopper's preferred brand (REPRSP), suggesting that frequent shoppers prone to use-by date are price sensitive and opportunistic.

\section{DISCUSSION}

It is clear from this study that the consumers' approach to label/packaging information is different when purchasing short-lived products as against purchasing products that do not have to be stored in refrigerated conditions. For example, when buying their regularly purchased perishable items, shoppers are not inclined to observe the label (LABREG in Table 1), but the regularity of their purchase does not appear to influence their inclination to observe the labels of preserved products (Table 2). Similarly, 
shoppers who ascribe more importance to the use-by date marked on the label/packaging of the product (IMPUBD) are likely to consider this feature when purchasing perishable items, but are not likely to consider the expiry date when purchasing items known to have a protracted life span when stored in ambient temperature. Older shoppers are also inclined to examine the use-by dates of their perishable purchases, but are not inclined to do so for purchases of items that are known to have an extended shelf life. The findings in both Tables 1 and 2, however, suggest that frequent shoppers (OFTEN) are likely 'use-by date prone' for both types of products. This result may be a consequence of frequent shoppers' likelihood of having more discretionary time to commit for observing the shelf life, particularly among unemployed shoppers of preserved items (EMPL). Use-by date prone shoppers for both types of products are also inclined to store their purchases as prescribed on the packaging (CARE). This result vindicates Tsiros and Heilman's (2005) findings that use-by date prone shoppers are inclined to preserve the age of item that they buy through storing the item in the way prescribed on the label. Only shoppers of preserved products ascribe satisfaction of their shopping experience in the store as a criterion in influencing them to observe the expiry date of their item. On the other hand, shoppers who run up higher bills during each shopping trip are less inclined to observe the expiry dates of only their perishable purchases (BILL). These shoppers are more inclined to take note of the perishable items' description (REGDES) and directions of use (REGDIR) ${ }^{14}$ and consider the language used on the label/packaging (IMPLAN) and the country where the item is produced (IMPCOU) as important elements that would influence them to examine the consumption time available on the perishable item. Country of origin (REGCOU, IMPADR) appears to be of interest even to use-by date prone shoppers of preserved items.

Shoppers of perishables believe that the item's brand (IMPNAM), ${ }^{15}$ composition (IMPCOM), ${ }^{16}$ label/packaging colour (IMPCOL) ${ }^{17}$ and font character (IMPFON) ${ }^{18}$ are not likely to influence them to observe the use-by dates of the products.

When purchasing perishable items, use-by date prone consumers respond to a short use-by date of their preferred perishable products by switching to an alternative brand (PREFUBD $=5$; ie purchasing an alternative brand with an ample use-by date from the same store), but are not prepared to buy a smaller pack of their preferred perishable items $(\mathrm{REFUBD}=3$; ie purchasing smaller size(s) of their preferred item), even though they could presumably replenish their stock in their next imminent visit to the store. There is no evidence that shoppers change their purchase behaviour for their preferred items when they do not have enough available consumption time, even if prices are discounted (PREFDIS), as this variable is not significant in influencing the estimated probability of examining the use-by dates.

According to the results in Table 1, shoppers who prefer store brands (HOMEB) are less likely to be use-by date prone. Australian shoppers are traditionally suspicious of store brands because of a common perception that they are cheap and nasty. Indeed, Australia lags behind the rest of the developed world in terms of the salience of home brands; AC Nielsen report that the store brand growth in Australia in the period 1996-2001 has only been 3 per cent, compared with the growth in the Organisation for Economic 
Cooperation and Development of 12 per cent. ${ }^{19}$ However, the pariah status of store brands in Australia is about to change. Porter $(2005)^{20}$ reports that two of Australia's biggest supermarket majors, namely Coles and Woolworth/Safeway, are actively considering introducing a suite of their own labels, albeit in the higher price categories. They are hoping that these store brands will be their engines of growth in the foreseeable future. As pointed out by Baltas (1997), however, ${ }^{21}$ the danger for store brands going up-scale is that they will forfeit their value-for-money customers and come head to head with the more reputed national brands. Miranda and Joshi (2003), however, note that if Australian retailers are able to ascribe a quality dimension to their store brands, they could still comfortably carve a niche in what is ordinarily considered the preserve of manufacturer brands. ${ }^{22}$

\section{Prospects for perishable items}

While store brand consumers of perishable items are not usually use-by date prone, the results of this research indicate that use-by date prone shoppers (of only perishable items) are inclined to consider other brands if the alternatives are perceived as offering a longer shelf life than their normal purchases. Having recognised that longer shelf life can be a significant explanatory criterion in the purchase decision of perishable products, a systematic claim of ample availability of use-by dates is a possible quality feature that the Australian retail majors could consider when promoting their new store brands of perishable items. Store brands are particularly suited to adopt this position because they ordinarily go through a shorter distribution chain than do manufacturer brands, as they save on transit time and cross-docking between intermediaries in the supply chain. These store brands of perishable products of milk, meat and vegetables available in several variants and multiple pack sizes, for instance, can potentially provoke an exodus from reputed manufacturer brands if the consumer perceives insufficient usage time from their preferred brands. Temporary price discounts of these new store brands, suitably claiming to have long shelf life, is likely to motivate early product adoption among the use-by date prone consumer segment, as the results in Table 1 indicate that these shoppers are likely to be attracted by price specials (REPRSP) on alternative brands of perishable products. ${ }^{23}$ Retailers using the expiry date plank to promote their store brands of perishable products may be well advised primarily to target frequent shoppers, specifically their older patrons, as this segment (AGE) is more likely to comprise the early adopters.

\section{CONCLUSION}

When breaking out several new brands, it is hard to find a suitable marketing position that allows them to be competitive against the established reputation of the national brands. This study evidenced that shoppers who are perceptive to products' shelf life are not particularly influenced by the discounted prices on items that are close to their expiry dates. Given an inventory management system that is as efficient as can be, brands of perishable items that can promise ample consumption time until their expiry dates would encourage those who are sensitive to use-by dates to try them out. To this extent, it would be useful for brands laying claims to pristine quality to corroborate this assertion by ensuring that their labels/packaging are appropriately designed, that relevant product cues are included and that they are appropriately targeted. 


\section{References and notes}

1 McCormack, B. (2002) 'Out-of-date: beyond the safety zone?' Available at: http://aca.ninemsn. com.au/factsheets/1077.asp (last accessed 17th May, 2005).

2 BBC News (2006) 'Colour-coded food labelling urged'. Available at: http://news.bbc.co.uk/ 1/hi/health/4788704.stm (last accessed 14th March, 2006).

3 Wright, L. T. (1997) 'Exploring the need for extended research: An investigation of consumer attitudes to product labeling', Journal of Product and Brand Management, Vol. 6, No. 6, pp. 417-427.

4 Davies, M. and Wright, L. (1993) 'The importance of labeling examined in food marketing', European Journal of Marketing, Vol. 28, No. 2, pp. 59-68.

5 Humphries, C. (1998) 'A code of practice for food labeling', Nutrition and Food Science, Vol. 98, No. 4, pp. 194-195.

6 Huq, F., Asnani, S., Jones, V. and Cutright, K. (2005) 'Modelling the influence of multiple expiration dates on revenue generation in the supply chain', International Journal of Physical Distribution \& Logistics Management, Vol. 35, No. 3, pp. 152-160.

7 Australian Government Department Health and Ageing (2003), 'Research confirms consumers are using food labels to make healthy choices'. Available at: http://www. Health.gov.au/international/wcms/ publishing.nsf/Content/health-mediarel-yr2003tw-tw03041.htm (last accessed 7th May, 2005).

8 Tsiros, M. and Heilman, C. (2005) 'The effect of expiration dates and perceived risks on purchasing behavior in grocery store perishable categories', Journal of Marketing, Vol. 69, No. 2, pp. 114-129.

9 Franses, P. H. and Paap, R. (2001) 'Quantitative models in marketing research', Cambridge University Press Cambridge, UK; Chapter 4.

10 Binary estimation option of EViews 5.1.

11 As there is an intercept term in the model, the first values of these categorical variables were treated as base categories and only the remaining five and three dummy variables were included in the model.

12 All unpublished details are available to interested readers on request.

13 The sample medians are as follows: $\mathrm{BILL}=3$, $\mathrm{AGE}=3, \mathrm{HOMEB}=2$, OFTEN $=3$, LABREG $=2$, REGDES $=1$, REGDIR $=1$, $\operatorname{IMPNAM}=3$, IMPCOU $=2, \operatorname{IMPCOM}=3$, $\operatorname{IMPUBD}=4, \mathrm{IMPCOL}=2, \mathrm{IMPFON}=2$,
$\operatorname{IMPLAN}=3,($ PREFUBD $=3)=0$, $(\mathrm{PREFUBD}=5)=0$.

14 The number of assortments available and variable usages of the items' variants is likely to prompt the use-by date prone shopper to seek help from the label's usage instructions.

15 When purchasing items that keep longer in ambient temperatures, shoppers do not believe that the importance that they ascribe to the source of the item (IMPNAM) would influence them to examine the product's expiry date, but in practice it appears that those concerned about the keeping quality of the product are inclined to observe the item's source (REGNAM).

16 This finding indicates that for regular users of a brand, familiarity with the make-up of the product tends to deflect their attention from the remaining shelf life of the product. National brands have a big advantage in this regard when they run low available shelf life.

17 This finding suggests that when the consumer consciously ascribes importance to label colour overlays (attractiveness) or, in other words, is 'distracted with the noise', the shopper is likely to be less cognitive about the use-by date of the item.

18 It appears that among shoppers of perishables, as opposed to shoppers of preserved products, the more importance that they ascribe to the label/packaging font character, the less likely they are to observe the item's expiry date. Well-designed labels that engage the attention of shoppers of perishable items can distract attention from short expiration dates.

19 Kerslake, D. (2001) 'Private labels fail public taste', Insight Asia Pacific, AC Nielsen, Causeway Bay, Hong Kong.

20 Porter, I. (2005) 'Home-brand strategy to take heavy toll', The Age, 2 April.

21 Baltas, G. (1997) 'Determinants of store brand choice: A behavioral analysis', Journal of Product and Brand Management, Vol. 6, No. 5, pp. 315-324.

22 Miranda, M. J. and Joshi, M. (2003) 'Australian retailers need to engage with private labels to achieve competitive difference', Asia Pacific Journal of Marketing and Logistics, Vol. 15, No. 3, pp. 34-47.

23 That use-by date prone shoppers are not beyond opportunism of getting better value for money is exemplified even by those seeking special deals (REGPRO) in Table 2 among shoppers of preserved items. 